\title{
On Audience Research in the New Media Context
}

\author{
LIU Shuchen \\ College of Computer Science and Engineering \\ Nanjing University of Science and Technology \\ Nanjing, Jiangsu 210094, China
}

\author{
Cao Wei \\ College of Communication \\ Nanjing University of the Arts \\ Nanjing, Jiangsu 210013, China
}

\begin{abstract}
The advent and growth of the new media has brought great changes to the role of the audience, the way the audience utilizes the media, and the reaction the audience make to the new media. This paper adopt the theory of development, the theory of use and gratification and the theory of encoding and decoding to analyze the importance of audience research.
\end{abstract}

Keywords- New Media; the Audience; Research

\section{INTRODUCTION}

There are countless new things coming up in the information and technology era. Characterized by digitization and interactivity, the advent of new media redefines and reclassifies the media communication sphere, setting itself apart from the traditional means of communication and expression, namely,television and broadcast, newspapers and magazines,books,etc, all referred to as the traditional media. The boom of new media has been changing the way that audiences utilize and respond to the media communication. And this radical change is promised to be pushed further with the constant development of the new media. In this view, this paper intends to make an analysis on the audience in the new media context, with the hope of revealing the changes and challenges facing the media communication and provoking the thought of create an active and positive coexistence of the new media and its audience.

\section{SHIFT OF AUdIENCE'S ROLE FROM PASSIVE RECEIVER TO ACTIVE SELECTOR TO INTERACTIVE PARTICIPANT}

To start with, this section will first introduce the concept of audience research. applying the theory from Sonia Livingstone and Ranjana Das' work. According to Sonia Living stone and Ranjana Das (2012), Audience studies are aimed at studying the convergence and divergence of audiences in understanding media content, the reaction of people after receiving the information and audiences participation in civil society. From this definition, it is obvious to see that the audiences' behaviours are the main body of the studies. The history of development of audiences is short, but it has a long past. "For audiences were not discovered in the 1980s, despite the attention attracted by
Stuart Hall's exciting new phase of research"(Sonia Livingstone and Ranjana Das, 2012). David Morley (1980) had written a book about the audience research, which was an expansion of Hall's hypothesis about decoding in the year 1973 (Boyd-Barrett, O., 1995). But there is also someone said the audience research began in Herta Herzog's research, which are radio listeners in the 1940s. The first recorded audience can be found in the ancient Rome's arenas and medieval theatres where audiences listened and watched the show. On some cases, they could also interact with the performers by shouting and applause. These audiences can still be found in modern society's theatres. The audiences have largely changed due to the development of technology in recent 100 years. In the very beginning, audiences were readers because they usually got news from daily newspapers. And then, the advent of radio has upgraded audiences from readers to listeners as they were not only able to see but to hear. Then comes the television, audiences were acting as viewers at this time as they can watch and listen what is happening on their televisions. In spite of some differences in the way how people use newspapers, radio and televisions, the audiences at this time period are considered to be relatively passive. The role of audiences has been changed again in the reason of the development of Internet technology. "At present, the language of users rather than audiences holds sway" (Sonia Livingstone and Ranjana Das, 2012), Internet users are more active compared to the old audience of instrumental media users. Internet users can choose to look at the news based on their interests by clicking on the website whenever and wherever their computers are connected to the internet without waiting for the newspaper or the TV programme at home. Users are not the end of the audience. As audiences are becoming more and more active, they are no longer satisfied with being a receiver of the messages. The audiences themselves are more willing to participate in the process of circulation of news and become the distributors of the information by using social networking apps and websites. The changing role of audiences revealed that audiences are seeking to be the more active audiences as they are eager to interacting with others. Asides from the history of the audience, the development of the media is also an important part of the audience research. The media has largely changed over the years, from the ancient theatres to mass media (referred to as newspapers, radio and television) and then to the Internet age. On the consideration of traditional audiences, they are active due to 
they always receive the information by themselves. For instance, people must purchase the radio, open it and then they can listen. It is the same as television viewers and theatre goers, people find the approaches to fulfil themselves, and they would not receive the messages if they do nothing or try incorrect methods. From this point, audiences are active, the right to get access to the messages is greatly determined by the audiences. However, this 'active' may be not equal to today's 'activity'. Such as BBM users, Skypers, YouTuber and uploaders, which demonstrate a great deal of politics and the attention to personal interests. Ann Gray (1999) argues this condition as the "bad projects" of the 'active audience'. He holds the opinion that this is a passive trend due to it ignores the feminist. Even though he admits that the version of the 'active audience' is hard to define, he found that many researchers focus on the circumstances and conditions for the listening, viewing and reading happening. This found can be seen in the past audience research.

\section{COGNITION SHIFT FROM MEDIA-CENTERED COMMUNICATION TO AUDIENCE-CENTERED COMMUNICATION}

In the early stage of the audience research, researchers tends to overestimate the effects of media on the audience focusing on its control over the audiences, regarding media as the authority to strongly influence gullible audiences. But their arguments have encountered some questions. Nick Couldry (2011) has concluded two paradigms in the early years. Abercrombie,N. and Longhurst, B. (1998) firstly questioned the ideological control of media and advocated more expression of audiences' diverse taste in the media context. The next is followed by the argument of media anthropologist Liz Bird (2003). Bird argues that media culture permeates in our daily lives, our practice being influenced by media to a large extent.

Indeed, the audiences are more in favor of the media that is close to their lives.

There is an example which reflects the problems on active audience. Robert Kubey (1996) has written an article about the television viewers. He uses Experience Sampling Method Findings to test the audience change after watching the television. The studies greatly show that television can bring viewers entertainment and ease the pressure very easily. Respondents are required to rank which is the most challenging for them in everyday activities. The result indicates watching television is the lowest challenge in comparison with other everyday work. In special, having dinner is higher than television. Kubey found another phenomenon and he named it 'passive spillover' effect. His respondents feel much more passive whatever they experience in the same day. What is more, viewers feel relax when watching the television, but after watching, they do not feel relax as they did before. Most of the audiences would rather to seeing the television programme which is similar to their lives than some characters they have never known. They also prefer the dreaming end of the drama, for instance, the lovers can get married finally, the victim will be rescued by the hero and the villain will be put into jail in the end. But not all the audiences' thoughts are the same. Audiences are affected by media, but some of the audiences may not. In fact, everyone is a special individual, they live in different environment and educate in different levels. It is hard to find any two individuals are in common with each other. In addition, audiences may not do what the media tell them to do. They just watch television programme for fun, but after turning off the television, it is difficult to judge how many they can remember.

This problem can be related to uses and gratifications studies. Uses and gratifications theory (UGT) is an approach to understanding why and how people actively seek out specific media to satisfy specific needs. UGT is an audiencecentered approach to understanding mass communication.Diverging from other media effect theories that question "what does media do to people?", UGT focuses on "what do people do with media?"Joseph Klapper (1963) argues that uses and gratifications focus more on effects. Because of the diversity of people's taste, the media may provide a certain degree to shape audiences characteristics. The audience's need for media is based on integration and social interaction, including keeping in touch with others social lives, acquainting themselves with strangers, which can get a sense of belonging, then set up communication basis, consistent social regulations and the desire to connect with families and friends. Another need for using the media is to entertain. Media always help audiences to divert from the reality, acquire intrinsic cultural or aesthetic experience. What is more, using media is a good way of killing time and making people less stressful as usual. It is better explained in people's liking of watching soap opera. 62 percent of the respondents are curious about the relationships with the characters. 40 percent of the respondents are thinking about the similar role in their real lives. The least portion of the respondents watch soap opera for entertainment and the most of the respondents are watching for escaping reality. This indicates that the media do affect the audience, but McQuail (2010) argues that the relation between the reaction of the media and the media use is very weak. For example, someone may feel relax after viewing the television, but he also can take a shower to relax. There are so many choices for the audiences, which mean media use is just the result of personal desire. The media is hard to meet all audiences' requirement due to different media context. On the contrary, the audiences are positive to choose the media, they select what they like to view and listen. Under this circumstance, uses and gratifications studies demonstrate the audiences are active in media.

\section{SHIFT OF AUDIENCE's INTERPRETATION :ADMITTING COLLECTIVE ACTION DEPENDING ON DIVERSITY,INDIVIDUALITY}

The Encoding/decoding model of communication was first developed by cultural studies scholar Stuart Hall in 1973. Titled 'Encoding and Decoding in the Television Discourse,' Hall's essay offers a theoretical approach of how media messages are produced, disseminated, and interpreted. His model claims that TV and other media audiences are 
presented with messages that are decoded, or interpreted in different ways depending on an individual's cultural background, economic standing, and personal experiences. In contrast to other media theories that disempower audiences, Hall advanced the idea that audience members can play an active role in decoding messages as they rely on their own social contexts, and might be capable of changing messages themselves through collective action.For example, since advertisements can have multiple layers of meaning, they can be decoded in various ways and can mean something different to different people.Hall claims that the decoding subject can assume three different positions: Dominant/hegemonic position, negotiated position, and oppositional position.

The audiences's requirements have been diversified, and multi-leveled with the increasing development of the new media, thus calling for corresponding responses from the media. In the new media age, there is a coexistence of different genres of media. One one hand, mass media under the new media context is characterized by the delivery of messages from point to plane, embodying the public and collective idea. On the other hand, the dismassified communication is characterized by the delivery of messages from points to points, embracing the diversity and individuality. With respect to audiences' requirements, there is a need for different audiences to obtain various information through different channels. Faced with the points to points media environment as well as the increasing occurrence of information, the audiences have the absolute right to choose and dominate.

The advent of internet communication has broken the dominance of traditional media and brought an end to the era of "channel hegemony"

Internet communication have the characteristics of "inclusiveness" and "openness"which the traditional media fall short of , making the communication popular, democratic and individual. Only by admitting the audiences' collective action depending on diversity, individuality can the new media best play its role.

\section{SHIFT OF THE INTERRELATIONSHIP BETWEEN THE MEDIA AND THE AUdIENCE: EVERYONE CAN BE THE SOURCE OF MEDIA AND ALSO THE MEDIA MAKER}

Traditional audiences only play the role of receiver, while nowadays, audiences are not likely to be too isolated . They can use their computers, smart phones or ipad by just clicking the icons quickly. These audiences are called 'users', it is the combination of readers, listeners and viewers. What is more, the audiences can make news themselves, they can be the broadcaster either in the age of Internet. A good case is the citizen journalists. Some users send the news they found to the Internet, for instance the popular online social platform, Weibo(Chinese Twitter). Owing to the large amount of people that use the Internet and these social media platforms, it is of high possibility that they are able to quickly notice the news that the professional journalists may not find. Moreover, the phone appliance and the widespread Internet, wifi gives the public priority to be the news maker.
Another change is that the media is everywhere, not only in the radio, television and computer, but also the street, the bus stop, the taxi and almost every public event. All that changes make the media diverse and make the audiences more complex. The audiences can also be the producers at the meantime, they are never be controlled by media any more. This demonstrates that the audience research becomes in some ways more challenging at present.

In the past, the functions of traditional media are providing information and entertainment. But now, polymedia adds to the function of communication in the age of new media. Users develop long-distance relationships through the polymedia. Under this circumstance, media become related to almost everyone. In addition, polymedia stresses that the users use this environment to choose the best suitable for them ( Madianou, M. and Miller, D. 2012). This is as similar as Nancy K. Baym's (2010) argument. In his book, he argues that the Internet helps all the users to set up their relationships beyond the space. Internet gives the users an efficient platform to meet friends, talking stories. It can be seen as a bridge to connect individual to society. He has noticed that in the forum of soap opera, most of the users become friends which based on similar tastes. They establish their friendships as a group quickly, and when others found the group, they will participant in it regardless of what type of the group it may be. Another interesting finding is that the users not only maintain old friends via the Internet platform, but also they build up relationship with strangers as well. In Haythornthwaite's (2002) view, it is inactive to keep relationships through the social circle, he referred to this condition as 'latent tie'. But Baym argues Facebook is a good way for 'latent tie'. The Facebook users can use friends' list to see which friend is online to chat with, and it is very convenient to find the potential friends in exist friends' list. Weibo also recommends some people to the users that they may take interest in. This function inspires the users to be active to find the friends, it gradually turns into a habit for each user to search for someone or something they want to know. The Internet provides an opportunity for users to share fresh events which can expand users' interests and horizon which in turn have an great impact on the media products. There is a good example of a famous TV show, American Idol. Jenkins, H. (2006) wrote 'Few can argue with American Idol's success'. There are more than 40 million audiences watched the final segment of the final episode of this amazing show. Jenkins analysed why it is so successful. He found that it may be attributable to American broadcasting change of the communication pattern. Another case in point is Chinese Spring Festival Gala broadcast by CCTV for over 30 years. The media industry tries to attract audiences' eyes and stimulates the audiences purchase desire and seals their determination. They found current media system was something wrong with the audiences position, new media discourse emphasizes the desires of the audiences. So, in the 1990s, there is a shift that media broadcasters began to focus on loyal audiences. Audiences prefer watching TV shows which meet their needs and tastes. After several years, Internet started to focus on the engagement of the audiences. Businessmen use this to build up brand 
reputation. They pay attention to audiences feels, emotions, which is different from the past. From the changing attitude of media industry, it can be seen that audiences are active nowadays, even the media has admitted this fact.

\section{CONCLUSION}

To be concluded, audience research is absolutely still significant in the age of internet. We should continue researching the audiences. The reasons are as follows. Firstly, the public are always audiences even they are changing with the development of the mass communication. Because 'users' are the combination of all they used to be. The texture of users is not changed because they are still audiences; they are more interactive at present. Secondly, new media is very complex for it is open to global audiences and it gradually concentrates on political matters. This directly results in the desire for the public to participate in civil society, democracy and social revolution. In this way, audiences become much more active to gain the right to give out their voice in the Internet. Thirdly, as a custom, media is still of great importance in terms of identity, and the role in people's daily life. And it is clear that media becomes more and more significant as new media is developing very rapidly. Technologies are updated as the time flies, the spread of communication becomes faster and wider. The past 50 years of audience research tells us, media mainly concentrates on context, readers, interpretation, meaning and active audiences. It will be more efficient to analyze the audiences rather than the media. Audience research has continued many years, the audience theories are critical, resistant and active as we can see, as a whole, and we should study further on audience research. As the media develops, I believe audience research will never stop.

\section{REFERENCE}

[1] Abercrombie,N. and Longhurst, B. (1998), Audiences: A Sociological Theory of Performance and Imagination, London: Sage.

[2] Ann Gray (1999), 'Audience and reception research in retrospect The trouble with audience', In Alasuutari, Pertti (Ed), Rethinking the media audience, London: Sage.

[3] Boyd-Barrett, O., \& Newbold, C. (1995), Approaches to Media: A Reader, London: Arnold.

[4] Hall, S. (1980), Encoding/Decoding. In S. Hall, D. Hobson, A. Lowe, \& P. Willis (Eds.), Culture, Media, Language London: Hutchinson.

[5] Hall, S. (1994), Reflections upon the Encoding/Decoding Model: An Interview with Stuart Hall. In J. Cruz \& J. Lewis (Eds.). Viewing, Reading, Listening: Audiences and Cultural Reception. Boulder: Westview Press. pp. 253-274.

[6] Haythornthwaite, C. (2002), Strong weak, and latent ties and the impact of new media. Information Society I8, 385-401.

[7] Jenkins, H. (2006), Convergence Culture. Where old and new media collide. New York: NYU Press.

[8] Joseph Klapper (1963), Mass communication research: An old road resurveyed. Public Opinion Quarterly 27: 515-527.

[9] Livingstone, S \& Das, R. (2012), The End of Audiences? Theoretical echoes of reception amidst the uncertainties of use. In Hartley, J. et.al. (Eds), Blackwell Companion to New Media Dynamics.

[10] Madianou, M. and Miller, D. (2012), 'Polymedia: towards a new theory of digital media in interpersonal communication', International Journal of Cultural Studies.

[11] McQuail (2010), McQuail's Mass Communication theory (6th edition). London: Sage.

[12] Nancy K. Baym (2010), Personal Connections in a Digital Age, Cambridge: Polity.

[13] Nick Couldry (2011), The necessary future of the audience... and how to research it. In Virginia Nightingale (Ed), The Handbook of Media Audiences. Cambridge, MA: Blackwell, pp. 213-229.

[14] Robert Kubey (1996), On not finding media effects: conceptual problems in the notion of an "Active" audience (with a reply to Elihu Katz). In James Hay, Lawrence Grossberg, Ellen Wartella (Eds), The Audience and Its Landscape. Boulder, Colorado: Westview Press. pp. 187-205. 